\title{
JPSE
}

(Journal of Physical Science and Engineering)

\section{Performance of Dye Sensitized Solar Cells (DSSCs) with ZnO Nanorod Electrode in Different Seed Solution}

\begin{tabular}{l}
\hline Received \\
31 August 2021 \\
Revised \\
13 October 2021 \\
Accepted for Publication \\
14 October 2021 \\
Published \\
18 October 2021
\end{tabular}

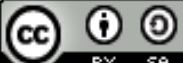

This work is licensed This work is licensed under a Creative Commons AttributionShareAlike 4.0 International Licens

\author{
H Pujiarti ${ }^{1,2^{*}}$, N A Astarini ${ }^{1}$, M Diantoro ${ }^{1,2}$, M S Aziz ${ }^{3}$ and R Hidayat ${ }^{4}$ \\ 1. Department of Physics, Faculty of Mathematics and Natural Sciences, Universitas Negeri \\ Malang, Jl. Semarang 5, Malang, 65145, Indonesia. \\ 2. Center of Advanced Materials for Renewable Energy, Universitas Negeri Malang, Jl. Semarang \\ 5, Malang, 65145, Indonesia. \\ 3. Department of Physics, Faculty of Science, Universiti Teknologi Malaysia, Johor Bahru, 81310, \\ Malaysia. \\ 4. Physics of Magnetism and Photonics Research Division, Faculty of Mathematics and Natural \\ Sciences, Institut Teknologi Bandung, Jl. Ganesha 10, Bandung, 40132, Indonesia.
}

*E-mail: herlin.pujiarti.fmipa@um.ac.id

\section{Introduction}

The urgent need for functional materials for optoelectronics, photocatalysis, spintronic, sensors, and solar cell applications continues to be researched for the development of harvesting energy. Dyesensitized solar cells (DSSCs) are an alternative silicon-based solar cell introduced by O'Regan and Gratzel in 1991. DSSCs have attracted considerable due to their potentially low fabrication cost, easy to control and fabricate the materials [1], [2]. The electrodes play a vital role in photovoltaic performance for DSSCs. It is well known that the electrode material for DSSCs must have key characteristics to show a good photovoltaic performance. They are must-have a high surface area, optimum pore size, good adhesions, light scattering ability, and electron acceptor ability [3]. ZnO nanorods as a prominent metal oxides material have been generally used for electrode because it has high thermal stability, non-toxicity, biocompatibility, good photoactivity, excellent photocatalytic, and potentially to increase the electron mobility accordingly increases the power conversion efficiency for DSSCs [1], [4]-[6].

$\mathrm{ZnO}$ which has a direct wide bandgap $(3.37 \mathrm{eV})$ is a metal oxide semiconductor material that has been identified as having a great potential for DSSCs [7]. DSSCs consist of several important components, a conductive substrate, a nanostructure semiconductor (electrode), a counter electrode, an electrolyte, and a visible-light absorber dye [8]. Previous studies have shown that $\mathrm{ZnO}$ nanorods with oriented and orderly epitaxial growth structures are very important for the development of new photovoltaic efficiencies of 3.15-4.46\% [1], [5], [9], [10]. Various methods have been successfully used for the synthesis of $\mathrm{ZnO}$ nanorods, such as low-temperature solution [11], chemical bath deposition 
[12], precipitation [13], pyrolysis [14], a sol-gel dip-coating technique [5], and sputtering [15]. However, the method requires controlled conditions under high temperature and pressure, thus limiting the commercialization of $\mathrm{ZnO}$ nanorods. Therefore, the seed solution-based hydrothermal method was chosen in the $\mathrm{ZnO}$ nanorod deposition process because of its low cost and easier fabrication process [1]. In this work, $\mathrm{ZnO}$ nanorods were prepared in two different seed solutions in isopropanol and methoxy. DSSC was prepared with FTO as a transparent conductive oxide, ZnO nanorods as an electrode, iodide electrolyte, D358 organic dye as a sensitizer, and Pt as a counter electrode. The morphological properties, the optical properties, and the power conversion efficiency (PCE) of DSSCs based $\mathrm{ZnO}$ nanorods will be examined.

\section{Method}

\subsection{Preparation of ZnO Nanorods Electrodes as a Photoanode}

The hydrothermal methods were used in this research. The $\mathrm{ZnO}$ nanorods were grown by two different seed solutions, namely sample 1 and sample 2 with methoxy and isopropanol, respectively. The FTO as a transparent conductive glass was cleaned with a standard procedure by using acetone followed by drying in an $\mathrm{N}_{2}$ gas atmosphere. In this experiment, we used $0.1 \mathrm{M}$ of seed layer precursors that were prepared from Zinc acetate dihydrate (Merck) as a zinc source. This material was dissolved in methoxy and isopropanol as a seed solution. The ZnO precursors were deposited on the FTO substrate by spin coating methods followed by the heating process. Afterward, the growth solution was prepared by the Zinc nitrate hexahydrate (Merck) and hexamethylenetetramine (HMTA) (Merck) in aquadest by stirring at room temperature for 30 minutes. Then the seed layer has been grown by hydrothermal technique in the growth solution with a temperature of $90{ }^{\circ} \mathrm{C}$ for $3 \times 2$ hours. The final step from this preparation is $\mathrm{ZnO}$ nanorod was washed by aquadest and ethanol followed by the last annealing of $500{ }^{\circ} \mathrm{C}$ for 30 minutes.

\subsection{Cell Assembly of DSSC}

The $\mathrm{ZnO}$ nanorods with different seed solutions as a photoanode were then made a sandwiching with the stacking structure DSSCs of FTO/ZnO nanorods/D358 organic dye/iodide-based electrolyte (mosalyte TDE 250)/Pt/FTO. The structure of DSSC was shown in Figure 1. The $\mathrm{ZnO}$ nanorods were soaked in the D358 organic dye solution for 24 hours in dark conditions and room temperature. The conductive area of the $\mathrm{ZnO}$ nanorod as a photoelectrode is separated with a $25 \mu \mathrm{m}$ melthonix spacer then sealed with the Pt counter electrode on each. The next step is the injection process of the iodide electrolyte into the cells through the vacuum process. Finally, we have a cell for further characterization process.

\subsection{Characterization of DSSC}

The SEM (Scanning Electron Microscopy) was carried out for investigating the morphology of $\mathrm{ZnO}$ nanorods electrodes. The optical properties of $\mathrm{ZnO}$ nanorods electrodes were investigated by UV-Vis spectroscopy. The photovoltaic characteristics of the DSSCs were carried out to investigate the current density $v s$. voltage $(J-V)$ measurements under the illumination of $100 \mathrm{~mW} / \mathrm{cm}^{2}$. The $J-V$ curve was carried out to determine the filling factor (FF) and efficiency.

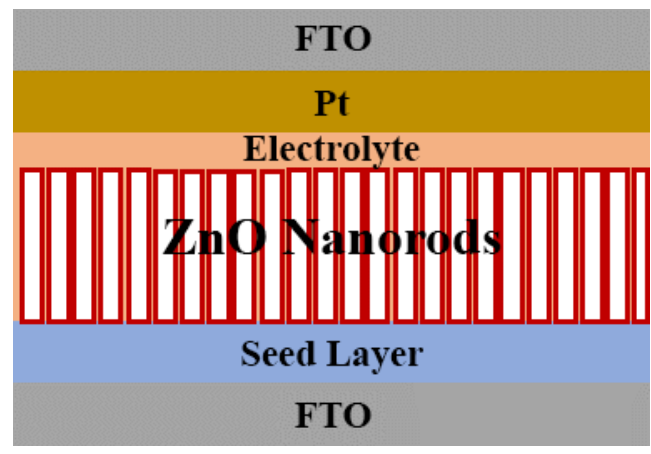

Figure 1. Structure of DSSCs based $\mathrm{ZnO}$ nanorods. 


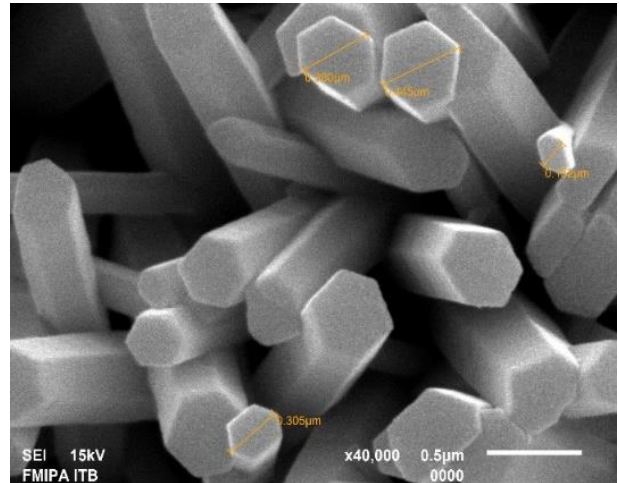

(a)

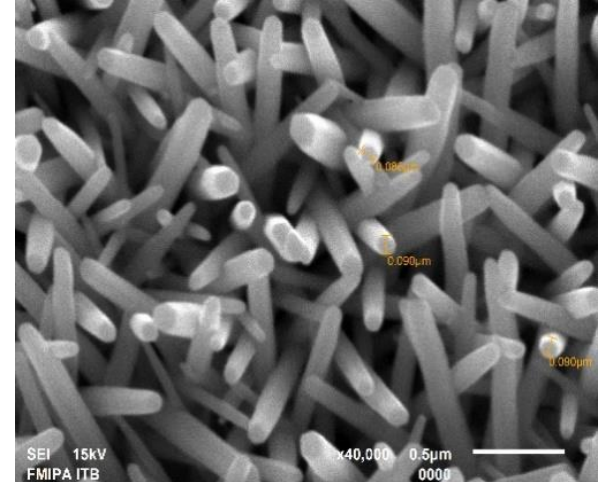

(b)

Figure 2. The SEM micrograph of $\mathrm{ZnO}$ nanorods with different seed solutions (a) Methoxy and (b) Isopropanol.

\section{Result and Discussion}

\subsection{The Morphology of $\mathrm{ZnO}$ Nanorods}

Figure 2 shows the SEM image of a $\mathrm{ZnO}$ nanorod array in a top view. From these figures, it can be seen that $\mathrm{ZnO}$ was successfully grown epitaxially on the FTO substrate. $\mathrm{ZnO}$ nanorods are formed with different diameter size. At a magnification of 40,000 times, the hexagonal structure of the sample is visible, the hexagonal shape of sample 1 (Figure 2a) is formed more clearly than sample 2 (Figure 2b). The difference in the growth of hexagonal rods is influenced by the seed solution used in the $\mathrm{ZnO}$ nanorod growth process. Sample 1 was grown in methoxy seed solution, while sample 2 was grown in isopropanol seed solution. These $\mathrm{ZnO}$ nanorods diameters are homogeneous with $0.337 \mu \mathrm{m}$ and 0.089 $\mu \mathrm{m}$ for sample 1 and sample 2, respectively. This proves that a smaller diameter of $\mathrm{ZnO}$ nanorod in isopropanol seed solution has the potential to increase dye absorption. The mechanism of increasing particle size depends on the coarsening-dominated system. Nucleation and growth and the degree of coarsening depend on the alcohol chain length (2-propanol and methoxy) [16].

\subsection{The Optical Properties of ZnO Nanorods}

The optical properties of $\mathrm{ZnO}$ nanorods were investigated by UV-Vis spectrum as shown in Figure 3. The absorbance spectrum of $\mathrm{ZnO}$ nanorods with isopropanol resulted in higher absorption than methoxy. The results of this work are in accordance with the research that has been done previously which proves that isopropanol has been shown to act as an appropriate solvent to control the growth orientation of $\mathrm{ZnO}$ thin films due to its suitable structural and optical properties [17]. The presence of isopropanol grows a larger area of rods and thus potentially results in higher absorbance levels.

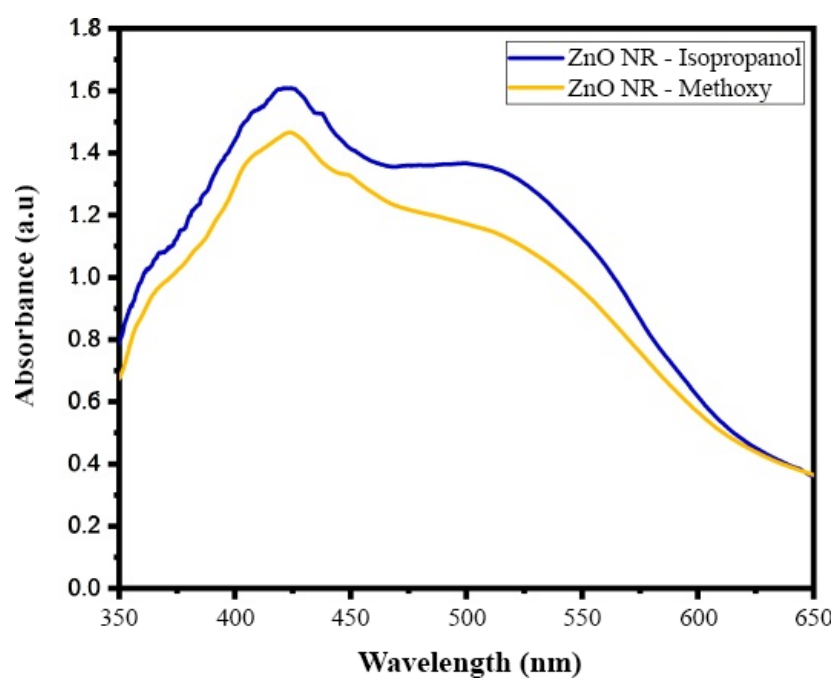

Figure 3. The UV-vis absorption spectrum of $\mathrm{ZnO}$ nanorod. 


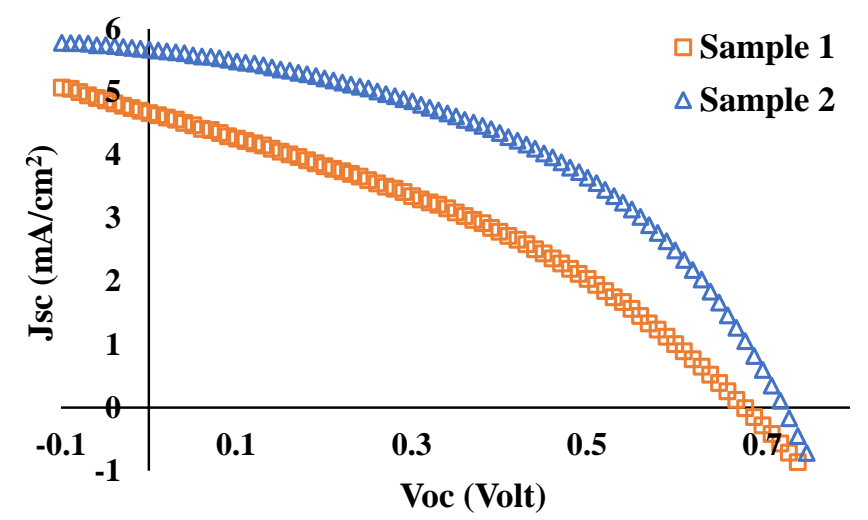

Figure 4. The photovoltaic characteristics of the DSSCs based on $\mathrm{ZnO}$ nanorod photoanodes.

Table 1. The parameters of DSSCs based on ZnO nanorods photoanodes.

\begin{tabular}{lcccc}
\hline Cells & $\begin{array}{c}\boldsymbol{J}_{\boldsymbol{s c}} \\
\left(\mathbf{m A} / \mathbf{c m}^{\mathbf{2}}\right)\end{array}$ & $\begin{array}{c}\boldsymbol{V}_{\boldsymbol{o c}} \\
(\mathbf{V o l t})\end{array}$ & FF & $\begin{array}{c}\text { PCE } \\
(\boldsymbol{\%})\end{array}$ \\
\hline Sample 1 & 4.6 & 0.68 & 35 & 1.1 \\
\hline Sample 2 & 5.6 & 0.72 & 45 & 1.8 \\
\hline
\end{tabular}

\subsection{The Photovoltaic Performance of DSSCs based ZnO nanorods}

Figure 4 shows the $(J-V)$ curves of DSSCs with $\mathrm{ZnO}$ nanorod in different seed solutions under the illumination of $100 \mathrm{~mW} / \mathrm{cm}^{2}$. In this study, DSSC was made in a sandwich structure consisting of FTO, $\mathrm{ZnO}$ nanorod as photoanode, D358 dye non-metallic indoline based as a sensitizer, iodide electrolyte, and Pt. The overall PCE of the DSSC is calculated from Equation 1 [18].

$$
\eta=\frac{P_{o u t}}{P_{i n}}=\frac{J_{s c} V_{o c} F F}{P_{i n}}
$$

The parameters of Equation 1 are current density voltage $\left(J_{s c}\right)$, open-circuit photovoltage $\left(V_{o c}\right)$, $F F$ of the cell, and the incident light intensity $\left(P_{i n}=100 \mathrm{~mW} / \mathrm{cm}^{2}\right)$. From these results, the PCE of sample 1 and sample 2 are $1.1 \%$ and $1.8 \%$, respectively. These results indicated that the photovoltaic performance of sample 2 is better than sample 1 .

The morphology and absorbance of $\mathrm{ZnO}$ nanorods were confirmed by the efficiency performance was tabulated in Table $1 . \mathrm{ZnO}$ nanorods with isopropanol with a diameter of $0.089 \mu \mathrm{m}$ resulted in the most optimum efficiency of $1.8 \%$. Based on previous research, it is known that isopropanol as a solvent or seed solution has more stable properties because it acts as a proton donor [19]. Previous research results have confirmed that the $\mathrm{ZnO}$ thin film preference growth axis indicates that the isopropanol is the best one [17]. This proves that the size of the diameter and absorbance at the photoanode which is influenced by a good seed solution will affect the performance of DSSCs. The smaller diameter of the $\mathrm{ZnO}$ nanorod in sample 2 provides a larger surface area then increasing the total amount of dye attached to the $\mathrm{ZnO}$ nanorod and improve the photovoltaic performance [20].

\section{Conclusion}

$\mathrm{ZnO}$ nanorods with a different seed solution were successfully fabricated. The photovoltaic performance of $\mathrm{ZnO}$ nanorod cells with isopropanol as solvent was higher than that of seed solution methoxy. The diameter size and higher absorption will result in a more optimum power conversion efficiency. $\mathrm{ZnO}$ nanorod using isopropanol with a diameter of $0.089 \mu \mathrm{m}$ produces the best efficiency of $1.8 \%$. The smaller diameter of the $\mathrm{ZnO}$ nanorod provides a larger surface area then increasing the total amount of dye attached to the $\mathrm{ZnO}$ nanorod and improve the photovoltaic performance.

\section{Acknowledgment}

The authors acknowledge financial support from PDD Kemenristek DIKTI 2020 and PNBP UM 2021. 


\section{References}

[1] T. Marimuthu, N. Anandhan, and R. Thangamuthu, "Electrochemical synthesis of onedimensional $\mathrm{ZnO}$ nanostructures on $\mathrm{ZnO}$ seed layer for DSSC applications," Appl. Surf. Sci., vol. 428, pp. 385-394, Jan. 2018, doi: 10.1016/j.apsusc.2017.09.116.

[2] S. S. Mali, J. V. Patil, and C. K. Hong, "Nanorod-based dye sensitized solar cells," in Nanomaterials for Solar Cell Applications, Elsevier, pp. 349-374, 2019, doi: 10.1016/B978-012-813337-8.00010-2.

[3] N. A. Karim, U. Mehmood, H. F. Zahid, and T. Asif, "Nanostructured photoanode and counter electrode materials for efficient Dye-Sensitized Solar Cells (DSSCs)," Sol. Energy, vol. 185, pp. 165-188, Jun. 2019, doi: 10.1016/j.solener.2019.04.057.

[4] I. Iwantono, S. K. Md Saad, R. Yuda, M. Y. Abd Rahman, and A. A. Umar, "Structural and properties transformation in $\mathrm{ZnO}$ hexagonal nanorod by ruthenium doping and its effect on DSSCs power conversion efficiency," Superlattices Microstruct., vol. 123, pp. 119-128, Nov. 2018, doi: 10.1016/j.spmi.2018.05.041.

[5] S. Kannan, N. P. Subiramaniyam, and Su. Lavanisadevi, "Controllable synthesis of ZnO nanorods at different temperatures for enhancement of dye-sensitized solar cell performance," Mater. Lett., vol. 274, p. 127994, Sep. 2020, doi: 10.1016/j.matlet.2020.127994.

[6] C. Wang, S. Luo, C. Liu, X. Liu, and C. Chen, "Photocatalytic performance of single crystal ZnO nanorods and $\mathrm{ZnO}$ nanorods films under natural sunlight," Inorg. Chem. Commun., vol. 114, p. 107842, Apr. 2020, doi: 10.1016/j.inoche.2020.107842.

[7] H. U. Chae, A. ul H. S. Rana, Y.-J. Park, and H.-S. Kim, "High-speed growth of ZnO nanorods in preheating condition using microwave-assisted growth method," J. Nanosci. Nanotechnol., vol. 18, no. 3, pp. 2041-2044, Mar. 2018, doi: 10.1166/jnn.2018.14971.

[8] K. Sharma, V. Sharma, and S. S. Sharma, "Dye-sensitized solar cells: Fundamentals and current status," Nanoscale Res. Lett., vol. 13, no. 1, p. 381, Dec. 2018, doi: 10.1186/s11671-018-27606.

[9] M. Saleem et al., "Solution processed $\mathrm{Zn1-x-ySmxCuyO}$ nanorod arrays for dye sensitized solar cells," Nanomaterials, vol. 11, no. 7, p. 1710, Jun. 2021, doi: 10.3390/nano11071710.

[10] A. Hezam et al., "Electronically semitransparent $\mathrm{ZnO}$ nanorods with superior electron transport ability for DSSCs and solar photocatalysis," Ceram. Int., vol. 44, no. 6, pp. 7202-7208, Apr. 2018, doi: 10.1016/j.ceramint.2018.01.167.

[11] A. Akshaykranth, T. V. Rao, and R. R. Kumar, "Growth of ZnO nanorods on biodegradable poly (lactic acid) (PLA) substrates by low temperature solution method," Mater. Lett., vol. 259, p. 126807, Jan. 2020, doi: 10.1016/j.matlet.2019.126807.

[12] P. K. Singh, B. Bhattacharya, and Z. H. Khan, "Environment approachable dye sensitized solar cell using abundant natural pigment based dyes with solid polymer electrolyte," Optik, vol. 165, pp. 186-194, 2018, doi: 10.1016/j.ijleo.2018.03.099.

[13] M. Yang et al., "High performance acetone sensor based on $\mathrm{ZnO}$ nanorods modified by $\mathrm{Au}$ nanoparticles," J. Alloys Compd., vol. 797, pp. 246-252, Aug. 2019, doi: 10.1016/j.jallcom.2019.05.101.

[14] S. Kumar, P. D. Sahare, and S. Kumar, "Optimization of the CVD parameters for ZnO nanorods growth: Its photoluminescence and field emission properties," Mater. Res. Bull., vol. 105, pp. 237-245, Sep. 2018, doi: 10.1016/j.materresbull.2018.05.002.

[15] M. A. K. Purbayanto et al., "Enhancement in green luminescence of $\mathrm{ZnO}$ nanorods grown by dcunbalanced magnetron sputtering at room temperature," Opt. Mater., vol. 108, p. 110418, Oct. 2020, doi: 10.1016/j.optmat.2020.110418.

[16] A. Moulahi and F. Sediri, "Controlled synthesis of nano-ZnO via hydro/solvothermal process and study of their optical properties," Optik, vol. 127, no. 19, pp. 7586-7593, 2016, doi: 10.1016/j.ijleo.2016.05.128.

[17] R. Bekkari et al., "Effect of solvents and stabilizer molar ratio on the growth orientation of solgel-derived $\mathrm{ZnO}$ thin films," Int. J. Photoenergy, vol. 2019, pp. 1-7, Feb. 2019, doi: $10.1155 / 2019 / 3164043$

[18] S. J. Dhoble, N. T. Kalyani, B. Vengadaesvaran, and A. K. Arof, Energy Materials Fundamentals to Applications. San Diego, California, USA: Elsevier, 2021. 
[19] C. Han et al., "Study on the components of isopropanol aqueous solution," Optik, vol. 155, pp. 307-314, Feb. 2018, doi: 10.1016/j.ijleo.2017.10.164.

[20] B. Zhai, L. Yang, and Y. M. Huan, "Improving the efficiency of dye sensitized solar cells by growing longer $\mathrm{ZnO}$ nanorods on TiO2 photoanodes" J. of Nanomaterials, vol. 2017, p. 1821837, 2017, doi: 10.1155/2017/1821837. 